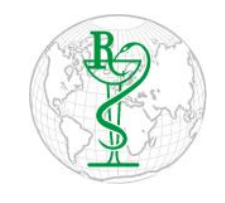

INDO GLOBAL JOURNAL OF

PHARMACEUTICAL SCIENCES

ISSN 2249- 1023

\title{
A Review on Impurity Profiling and its Regulatory Aspects- An Important and Necessary Tool in Stability Studies
}

\author{
Ameena Yasmeen ${ }^{1,2 *}$, Ghulamuddin Sofi ${ }^{2}$, Kaleemullah Khan ${ }^{3}$ \\ ${ }^{I}$ Dept. of Ilmul Advia, Govt Unani Medical College \& Hospital, Siddaiah Puranik Road, Basaveshwaranagar, Rajiv Gandhi University of Health \\ Sciences, Bangalore, Karnataka, India. \\ ${ }^{2}$ Dept. of Ilmul Advia, National Institute of Unani Medicine, Kottigepalya, Rajiv Gandhi University of Health Sciences, Bangalore, Karnataka, \\ India. \\ ${ }^{3}$ Private Practitioner and Independent Researcher, Mysore, Karnataka, India
}

Address for Correspondence: Ameena Yasmeen, ameena2309@gmail.com

\begin{abstract}
Received:
19.10.2019

Accepted:

09.03.2020

Published:

07.11.2020

Keywords

Unani Medicine;

Crude Drugs;

Stability studies;

Heavy Metals;

Impurity

Profiling;

International

Conference on

Harmonization

(ICH)

Guidelines..
\end{abstract}

\begin{abstract}
The chemistry of plants is as divergent as the great variety of forms in which plants occur. The therapeutically important constituents are usually found to be associated with many inert substances. The active principles are extracted from plant drugs and purified for therapeutic utility for their selective and regulated activity. The quality control of the herbal crude drugs and their bio constituents is of paramount importance in justifying their acceptability for present pharmaceutical industry standards. One of the major problems faced by the user industry is the non-availability of rigid quality control profiles for herbal raw materials and their formulations. It is, discovered that the crude drugs in commerce are often adulterated and don't go with the standards prescribed for authentic drugs. The cornerstones of bringing new medicines to market are quality, safety, and efficacy. These attributes are controlled using a variety of analytical procedures aimed at characterizing drug substance and drug product purity. A key step of delivering on these aspects is a detailed understanding of the impurity profile of a drug substance and the final product. Unani drugs have to go through stability testing as it has been made mandatory through regulatory authorities from 2019. Though it was notified in 2017 two years were provided to tune with the guidelines. The present paper summarizes the concept of impurity profiling from its basics to its regulatory aspects in detail as a preliminary guide and is part of the larger study related to stability studies of single drugs of Unani medicine. Hence there is a need for impurity profiling of the crude drugs. The other part of the study that details about the protocol for stability testing for the Unani drugs will be communicated in the near future. (C) 2020 iGlobal Research and Publishing Foundation. All rights reserved.
\end{abstract}

Cite this article as: Yasmeen, A.; Sofi, G.; Khan, K. A review on impurity profiling and its regulatory aspects- an important and necessary tool in stability studies. Indo Global J. Pharm. Sci., 2020; 10(1): 57-68. DOI: http://doi.org/10.35652/IGJPS.2020.10108 .

\section{INTRODUCTION}

After collection of the crude drugs, they are required to be processed prior to marketing. The reasons for preparation of crude drugs are to stabilize them in transport and storage and to make sure the absence of foreign organic matter and substitutes. Market preparation of the crude drugs also takes care of pharmaceutical elegance. While preparing a drug of commerce, several methods are adopted to meet the standard Pharmacopoeial requirements. Generally, these methods include, proper methods of collection, harvesting, drying and garbling. Sometimes, coating and bleaching is also necessary for converting the drug into suitable form for the market. While doing so, it should be taken care that neither the action of the drug lowers nor does it change, due to the additives used in the process, or due to the reactions between the drug and the excipients, etc. [1].

One of the most important considerations in the drug discovery process is safety [2]. Not only purity profile, but now-a-days, even the impurity profile has become mandatory according to various regulatory authorities. Impurity profiling study has been in the limelight in the recent pharmaceutical scenario and its importance is increasing day-by-day [3]. The role of impurity analysis is dynamic and conducted throughout the pharmaceutical drug development process. Impurity based 
Indo Global Journal of Pharmaceutical Sciences, 2020; 10(1): 57-68

activities throughout the development of therapeutics are uniquely focused in terms of their application needs as the drug product progresses downstream to commercialization. The analysis of pharmaceutical raw materials and finished product for impurities and degradation product is an important aspect of the drug development testing and preparation method. Additionally, toxicological information must be obtained on any drug-related impurity that is present at a concentration of greater than $0.1 \%$ of that of the active pharmaceutical ingredient (API) [4]. Even trace level of impurities will adversely have an effect on both the safety and efficacy of the pharmaceutical drug product. Some of the impurities formed can also be mutagenic or teratogenic. Thus, there is a need for controlling the level of impurities present within limits in both drug substances and drug products [5].

Impurities that are within the API need to be traced to ascertain that no cancerous or harmful substances are going to be administered to patients. Drug product degradation profiles ought to be established to guide stable formulation and give appropriate drug shelf life assessment. Structural characterization of impurities and degradation products in bulk drug substances is an integral part of pharmaceutical product development [2].

The latest Guidance's that have been issued are related to:

- Stability methods (ICH Q1A-F, 1996-2003),

- Drug Substance/ Drug Product Impurities (ICH Q3AQ3B, 2006),

- Genotoxic impurities (ICH S2R1, 2011 \& M7, 2014),

- Extractables and Leachables (ICH Q8-Q9, 20052009), and

- Life Cycle Management (ICH Q12, 2014).

In addition, therapeutic molecules are becoming more and more complex, giving rise to greater analytical challenges [4]. Drug regulatory agencies also have requirements for characterization of the impurity profile of a pharmaceutical [2]. Various regulatory authorities like USFDA, ICH, Canadian Drug and Health Agency have regulated the control of impurities in new drug substances, formulated products and active pharmaceutical ingredients and are emphasizing on the purity requirements and the identification of impurities in active pharmaceutical ingredient's (API's) [3]. The review has emphasized over the impurity profiling as a necessary tool for shelf life studies along with its regulatory guidelines.

\section{Regulatory Aspects of Impurities and Impurity Profiling}

Until the start of the twentieth century, drug product was made and sold-out having no obligatory management. Quality was generally poor. Many products were patent medicines of dubious value. Some were harmful and addictive. In 1937, ethylene glycol was used as a vehicle for an elixir of sulphanilamide, which caused more than 100 deaths [6]. Thereupon the Food, Drug and Cosmetic act was revised requiring advance proof of safety and various other controls for new drugs. The impurities to be considered for new drugs are listed in regulatory document of the Food and Drug Administration (FDA) [7], International Conference on the Harmonization of the Technical Requirements for Registration of Pharmaceuticals for Human Use (ICH) [8], and the United States Pharmacopoeia (USP) [9]. The USP and National Formulary (NF) are the recognized standards for potency and purity of new drugs. These compendia have become official upon adoption of the first food and drug act. They formulate legal standards of quality, purity and strength of new drugs [10]. The ICH, which took place in Yokohama, Japan in 1995, has released new guidelines on impurities in new drug products [11]. These guidelines have a number of advantages, both for the industry and the regulators. The guidelines not only aid the sponsors of New Drug Applications (NDA) or Abbreviated New Drug Application (ANDA) with the type of information that should be submitted with their applications, but also assist the FDA reviewers and field investigators in their consistent interpretation and implementation of regulations [3].

\section{Synonyms of Impurities}

The synonyms of impurities includes, By-products, Degradation products, Interaction products, Intermediates, Penultimate intermediates, Related products, Transformation products and Residual solvents [12].

\section{Definition of Impurity}

Impurity is defined according to the International Conference on Harmonization of Technical Requirements for the Registration of Pharmaceuticals for Human Use (ICH) guideline on impurities in new drug substances as, "Any component of the new drug substance that is not the chemical entity defined as the new drug substance." Impurities can be formed during drug synthesis, manufacturing, and/or storage $[13,14]$.

The ICH guidance on impurity has clearly outlined the degree of poisonous impurities and became a benchmark in establishing impurities in pharmaceutical drug preparations. Impurities in prescribed drugs are the unwanted chemicals that stay with the active pharmaceutical ingredients (APIs), or develop during formulation, or upon aging of both API and formulated APIs to medicines, arising from normal manufacture. They are not chemicals accidently or maliciously introduced. Impurities don't have any therapeutic worth and are seriously harmful. Therefore, they need to be controlled $[15,16]$. Depending whether or not certain threshold (concentration) limits are exceeded, these drug impurities should be identified, qualified and/or quantified [13]. For this purpose, many pharmaceutical industries develop a drug impurity profile. Impurity profile is nothing but, "The description of identified and unidentified impurities present in a new drug substance." [13]. Impurity checking includes, identification, structure elucidation and quantitative determination of impurities and degradation products in bulk drug materials and pharmaceutical formulations [17]. In pharmaceutical quality control and manufacture, impurity analysis has traditionally been performed by HPLC with UV, 


\section{Indo Global Journal of Pharmaceutical Sciences, 2020; 10(1): 57-68}

PDA, or MS detection. As it is essential to detect and measure all of the impurities in the sample, it is necessary to have a high resolution separation process [4]. In the present scenario, the usage of new analytical techniques, like UPLC, LC-MS, GC-MS, SFC-MS, LCNMR, CE-MS etc., are in vogue. [2]. Analytical technology advances such as UPLC and UPC offer significant improvements in throughput and sensitivity, with benefits to the process of product release and identification of drug-related impurities [4].

\section{Classification of Impurities}

According to ICH guidance, impurities in drug substance made by chemical synthesis will be generally classified into following 3 classes:

1. Organic Impurities (Process and drug-related)

2. Inorganic Impurities (Reagent, ligands, catalysts)

3. Residual Solvents (Volatile solvents) [13].

According to United States Pharmacopoeia (USP) impurities are classified into:

1. Impurities in official Articles

2. Ordinary Impurities

3. Organic Volatile Impurities [9].

Organic impurities will arise throughout the producing method and/or storage of the new drug substance. They will be identified or unidentified, volatile or nonvolatile, and include:

- Starting materials,

- By-products

- Intermediates

- Degradation products

- Reagents, ligands, and catalysts [13].

Inorganic impurities can result from the manufacturing process. They are normally known and identified and include:

- Reagents, ligands and catalysts

- Heavy metals or other residual metals

- Inorganic salts

- Other materials (e.g., filter aids, charcoal) [13].

Solvents are inorganic or organic liquids used as vehicles for the preparation of solutions or suspensions within the synthesis of freshly prepared drug substance. Since these are generally of known toxicity, the choice of acceptable controls is well accomplished (see ICH Q3C on Residual Solvents detailed below) [13].

\section{Rationale for the Reporting and Control of Impurities}

\section{A. Organic Impurities}

The applicant should summarize the actual and potential impurities most likely to arise during the synthesis, purification, and storage of a new drug substance. This outline ought to be supported by sound scientific appraisal of the chemical reactions concerned within the synthesis, impurities associated with raw materials that could contribute to the impurity profile of the new drug substance, and possible degradation products. This discussion will be restricted to those impurities which may fairly be expected by the data of the chemical reactions and conditions concerned. In addition, the applicant should summarize the laboratory studies conducted to detect impurities in the new drug substance. This summary should include test results of batches manufactured during the development process and batches from the proposed commercial process, as well as the results of stress testing (as per the guideline, ICH Q1A(R) on stability), used to identify potential impurities arising during storage. The impurity profile of the drug substance batches meant for selling ought to be compared with those utilized in development, and any differences discussed [13].

Any impurity at a grade higher than (>) the identification threshold in any batch prepared by the planned industrial method ought to be known. In addition, any degradation product observed in stability studies at recommended storage conditions at a level greater than (>) the identification threshold should be identified. When identification of the impurity isn't possible, a summary of the laboratory studies demonstrating the unsuccessful effort should be included in the application. Where planning has been implied to spot impurities which are at levels of no more than $(<)$ the identification thresholds. Identification of impurities present at an apparent level of not more than $(<)$ the identification threshold is generally not considered necessary. However, analytical procedures should be developed for those potential impurities that are expected to be unusually potent, producing toxic or pharmacological effects at a level not more than $(<)$ the identification threshold. The Maximum daily dose, Reporting, Identification and Qualification Thresholds are listed in the Table 1 [13].

Table 1: The standard Thresholds for identification and qualification of Impurities [13]

\begin{tabular}{|l|l|l|l|}
\hline $\begin{array}{l}\text { Maximum } \\
\text { Daily } \\
\text { Dose [1] }\end{array}$ & $\begin{array}{l}\text { Reporting } \\
\text { Threshold } \\
{[\mathbf{2 , 3 ]}}\end{array}$ & $\begin{array}{l}\text { Identification } \\
\text { Threshold [3] }\end{array}$ & $\begin{array}{l}\text { Qualification } \\
\text { Threshold [3] }\end{array}$ \\
\hline$\leq 2 \mathrm{~g} /$ day & $0.05 \%$ & $\begin{array}{l}0.10 \% \text { or } 1.0 \\
\text { mg per day } \\
\text { intake } \\
\text { (whichever is } \\
\text { lower) }\end{array}$ & $\begin{array}{l}0.15 \% \text { or } 1.0 \\
\text { mg per day } \\
\text { intake } \\
\text { (whichever is } \\
\text { lower) }\end{array}$ \\
\hline$>2 \mathrm{~g} /$ day & $0.03 \%$ & $0.05 \%$ & $0.05 \%$ \\
\hline
\end{tabular}

Note: 1 . The amount of drug substance administered per day.

2. Higher reporting thresholds should be scientifically justified.

3. Lower thresholds can be appropriate if the impurity is unusually toxic.

\section{B. Inorganic Impurities}

Inorganic impurities are normally detected and quantified using Pharmacopoeial or other appropriate procedures. Carryover of catalysts to a new drug substance should be evaluated 


\section{Indo Global Journal of Pharmaceutical Sciences, 2020; 10(1): 57-68}

during development. The need for inclusion or exclusion of inorganic impurities in a new drug substance specification should be discussed. The acceptance criteria should be based on Pharmacopoeial standards or known safety data [13].

\section{Solvents}

Solvents in pharmaceuticals are defined here as organic volatile chemicals that are used or produced in the manufacture of drug substances or excipients, or in the preparation of drug products. The solvents are not completely removed by practical manufacturing techniques. Appropriate selection of the solvent for the synthesis of drug substance may enhance the yield, or determine characteristics such as crystal form, purity, and solubility. Therefore, the solvent may sometimes be a critical parameter in the synthesis process. The control of residues of the solvents used in the manufacturing process for a new drug substance should be discussed and presented according to ICH Q3C Impurities: Residual Solvents [13].

\section{Analytical Procedures}

A registration application ought to embody documented proof that the analytical procedures are valid and appropriate for the detection and quantification of impurities [18, 1]. The use of 2 decimal places for thresholds (see Table 1) doesn't essentially signify the exactness of the analytical procedure used for routine quality control methods. Thus, the utilization of lower precise techniques (e.g., thin-layer chromatography) may be acceptable wherever needed and suitably applied. Differences within the analytical procedures used throughout development and suggested procedures planned for the industrial production ought to be mentioned within the registration application. The quantitation limit for the analytical procedure should be not more than $(\leq)$ the reporting threshold [13].

Organic impurity levels may be measured by a range of techniques, together with those which compare an analytical response for the impurity with that of an acceptable reference standard or to the response of the new drug substance itself. Reference standards utilized in the analytical procedures for management of impurities ought to be evaluated and characterized in accordance with their supposed uses. The drug substance may be used as a standard to estimate the degree of impurities. In cases wherever the response factors of a drug substance and therefore the relevant impurity aren't matching, this observation will still be acceptable, provided a correction method is applied or the impurities are, in fact, being overestimated. Acceptance criteria and analytical procedures accustomed to estimate identified or unidentified impurities may be implied by analytical assumptions (e.g., equivalent detector response). These assumptions should be discussed in registration applications [13].

\section{Reporting Impurity Content of Batches}

Analytical results ought to be provided in an application for all batches of a fresh drug substance used for clinical, safety, and stability testing, likewise as for batches representative of the proposed commercial process. Quantitative results ought to be given numerically and not generally in terms like "complies" or "meets limit." Any impurity at a level greater than (>) the reporting threshold (Table 1) and total impurities observed in these batches of the new drug substance should be reported with the analytical procedures indicated. Below 1.0 percent, the results ought to be reportable to 2 decimal places (e.g., 0.06 percent, 0.13 percent); at and higher than one. 0 percent, the results should be reported to one decimal place (e.g., 1.3 percent). Results should be rounded using conventional rules. A Tabulation (e.g., spreadsheet) of the data is recommended. Impurities ought to be selected by code number or by an acceptable descriptor (e.g., retention time). If a better reporting threshold is planned, it ought to be absolutely correct. All impurities at a level greater than (>) the reporting threshold should be summed and reported as total impurities [13].

When analytical procedures modify along the course of development, reported results ought to be connected to the procedure used, with applicable validation data provided. Representative chromatograms should be provided. Chromatograms of representative batches from analytical validation studies showing separation and detectability of impurities (e.g., on spiked samples), besides the other impurity tests habitually performed, will act as the representative impurity profiles. The applier ought to make sure that they complete impurity profiles (e.g., chromatograms). Tabulation ought to be given, that links the particular new drug substance batch to every safety study and every clinical study during which the new drug substance has been used [13].

For each batch of the new drug substance, the report should include:

Batch identity and size, date of manufacture, site of manufacture, manufacturing process, impurity content, individual and total use of batches, and reference to analytical procedure used [13].

\section{Listing of Impurities in Specifications}

The specification for a brand new drug substance ought to contain a listing of impurities. Stability studies, chemical development studies, and routine batch analyses can be used to predict those impurities likely to occur in the commercial product. The selection of impurities in a new drug substance specification ought to be based on the impurities found in batches prepared by the planned marketing method. Those individual impurities with specific acceptance criteria mentioned within the specification for a brand new drug substance are cited as specified impurities within this guideline [13].

\section{Specified impurities can be Identified or Unidentified.}

An explanation for the inclusion or exclusion of impurities in specification ought to be mentioned. The explanation ought to imply a discussion of the impurity profiles discovered within the safety and clinical development batches, besides considering the impurity profile of batches prepared by the proposed marketing process. 


\section{Indo Global Journal of Pharmaceutical Sciences, 2020; 10(1): 57-68}

Specified identified impurities should be included along with specified unidentified impurities estimated to be present at a level greater than (>) the identification threshold given in Table 1 [13]. For impurities best-known to be remarkably potent or to provide harmful or sudden pharmacological effects, the quantitation/detection limit of the analytical procedures should be commensurate with the level at which the impurities should be controlled [13].

For unidentified impurities, the procedure used and assumptions created in establishing the extent of the impurity ought to be clearly expressed. Specified, unidentified impurities ought to be mentioned by an acceptable qualitative analytical, descriptive label (e.g., "unidentified A", "unidentified with a relative retention of 0.9 " etc.) [13].

A general acceptance criterion of no more than $(\leq)$ the identification threshold (see Table 1) for any unspecified impurity and an acceptance criterion for total impurities ought to be enclosed. Acceptance criteria ought to be set no more than the amount which will be justified by safety information and may be in line with the amount accomplished by the preparation method and the analytical capability. Where there's no safety concern, impurity acceptance criteria ought to be in accordance with the information generated on batches of a brand new drug substance prepared by the planned marketing method, allowing sufficient latitude to handle general preparation and analytical variation and also the stability characteristics of the new drug substance. Although general preparation variations are expected, significant variation in batch-to-batch impurity levels can indicate that the manufacturing process of the new drug substance is not adequately controlled and validated (see ICH Q6A guidance on specifications, detailed below (Figure 1, for the Decision Tree, for establishing an acceptance criterion for a specified impurity in a new drug substance). The use of 2 decimal places for thresholds (Table 1) do not essentially indicate the preciseness of the acceptance criteria for specified impurities and total impurities [13].

In summary, a brand new drug substance specification ought to embody, wherever applicable, the below mentioned list of impurities:

- $\quad$ Organic Impurities
- Each specified identified impurity
- Each specified unidentified impurity
of no morecified impurity with an acceptance criterion $(\leq)$ the
identification threshold
- Total impurities
- $\quad$ Residual Solvents
- $\quad$ Inorganic Impurities.

\section{Qualification of Impurities}

Qualification is the method of acquiring and evaluating information that establishes the biological safety of any one impurity or a given impurity profile at the level(s) fixed. The applier ought to explain establishing impurity acceptance criteria that have safety issues. The level of any impurity that is present in a new drug substance that has been adequately tested in safety and/or clinical studies would be taken as qualified. Impurities which are even important metabolites too, prevailing in animal and/or human studies are usually taken as qualified. A level of a certified impurity above that prevailing in a new drug substance may be applied based upon an analysis of the particular quantity of impurity administered in previous relevant safety studies [13].

If information is unobtainable to qualify the suggested acceptance criterion of an impurity, studies to get such information will be accepted once the standard qualification thresholds given in Table 1 are exceeded. Higher or lower thresholds for the qualification of impurities will be acceptable for a few individual drugs based upon scientific explanation and level of concern, as well as drug class effects and clinical expertise. For example, qualification will be particularly vital once there's proof that such impurities in any drug or therapeutic classes have before been related to adverse reactions in patients. In these instances, a lower qualification threshold will be acceptable. Conversely, a greater qualification threshold will be accepted for individual medication once the extent of concern for safety is a smaller amount than usual based upon similar issues (e.g., patient population, drug class effects, and clinical considerations). Proposals for alternative thresholds would be considered on a case-by-case basis [13]. The "Decision Tree for Identification and Qualification" (Figure 1) describes considerations for the qualification of impurities when thresholds are exceeded. In some cases, decreasing the amount of impurity to no more than the threshold will be easier than providing safety information. Alternatively, adequate information may be accessed within the scientific literature to qualify an impurity. If neither is that the case, further safety testing ought to be thought of. The studies thought of acceptable to qualify an impurity can depend upon a variety of things, including the patient population, daily dose, and route and duration of drug administration. Such studies will be conducted on the new drug substance containing the impurities to be controlled, although studies using isolated impurities can sometimes be appropriate [13].

Although this guideline isn't meant to be used in the clinical research stage of development, in the later stages of development, the thresholds in this guide can be useful in evaluating new impurities discovered in drug substance batches manufactured by the planned marketing method. Any new impurity discovered in later stages of development ought to be known if its level is higher than (>) the identification threshold is given in Table $\mathbf{1}$ and Figure 1. Similarly, the qualification of the impurity should be considered if its level is greater than (>) the qualification threshold given in Table1. Safety assessment studies to qualify an impurity ought to compare the new drug substance containing a representative quantity of the new impurity with the already qualified material. Safety assessment studies employing a sample of the isolated impurity may be thought of [13]. 
Indo Global Journal of Pharmaceutical Sciences, 2020; 10(1): 57-68

Figure 1: Decision Tree for Identification and Qualification of a Degradation product.

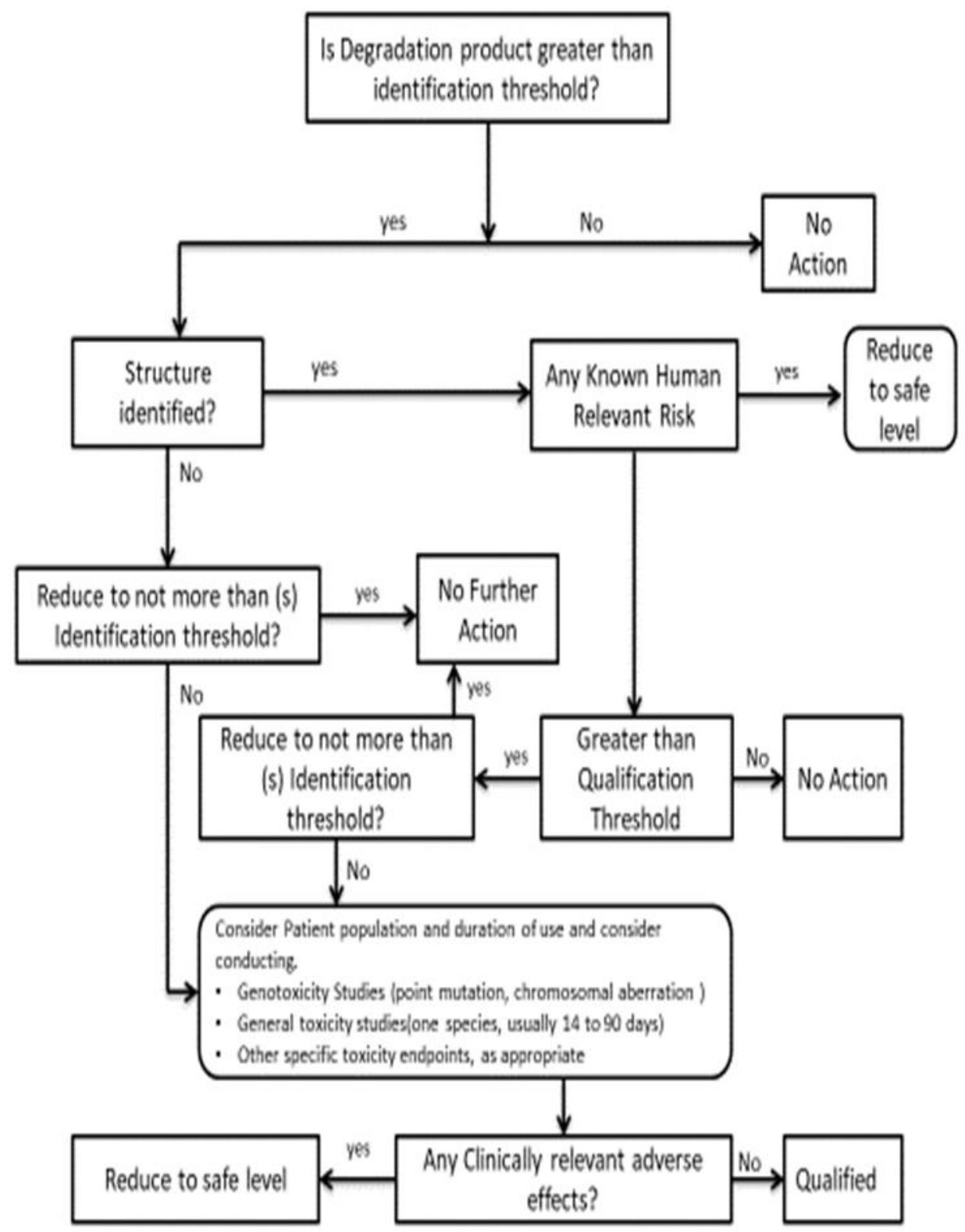

Reporting Impurity Results for Identification and Qualification in an Application

1. After identification, if the response factor is determined to differ significantly from the original assumptions, it may be appropriate to remeasure the actual amount of the impurity present and re-evaluate against the qualification threshold (see Table 1).

2. To verify if a threshold is exceeded, a reported result should be evaluated against the thresholds as follows:
- When the threshold is described in \%, the reported result rounded to a similar decimal place because the threshold ought to be compared straightly to the threshold.

- When the threshold is described in TDI, the reported result should be converted to TDI, rounded to the same decimal place as the threshold, and compared to the threshold. For example, the amount of impurity at $0.12 \%$ level corresponds to a TDI of $0.96 \mathrm{mg}$ (absolute amount), which is then rounded up to $1.0 \mathrm{mg}$; so the qualification threshold expressed in TDI $(1.0 \mathrm{mg})$ isn't exceeded [13]. 
Indo Global Journal of Pharmaceutical Sciences, 2020; 10(1): 57-68

\section{An Overview on the Various Regulatory}

\section{Guidelines on Impurities [20]}

There are various regulatory guidelines on impurities that are described briefly as well as listed in Table 2 for a quick reference.

Table 2-Overview of regulatory guidelines on impurities

\begin{tabular}{|c|c|c|c|}
\hline $\begin{array}{l}\text { Serial } \\
\text { No } \\
\end{array}$ & Standard & $\begin{array}{ll}\begin{array}{l}\text { Title } \\
\text { references }\end{array} & \& \\
\end{array}$ & Date \\
\hline 1. & ICH Q1A(R2) & $\begin{array}{l}\text { Stability Testing } \\
\text { of New Drug } \\
\text { Substances and } \\
\text { Products }[18,20]\end{array}$ & 2003 \\
\hline 2. & ICH Q2B & $\begin{array}{l}\text { Validation of } \\
\text { Analytical } \\
\text { Procedures: } \\
\text { Methodology } \\
{[20,21]}\end{array}$ & 1996 \\
\hline 3. & ICH Q3A(R) & $\begin{array}{lr}\text { Impurities } & \text { in } \\
\text { New } & \text { Drug } \\
\text { Substances } & {[20,} \\
13] & \\
\end{array}$ & 2002 \\
\hline 4. & ICH Q3B(R) & $\begin{array}{lr}\text { Impurities } & \text { in } \\
\text { New } & \text { Drug } \\
\text { Products } & {[20,} \\
22] & \end{array}$ & 2003 \\
\hline 5. & ICH Q3C(R6) & $\begin{array}{l}\text { Impurities: } \\
\text { Guidelines for } \\
\text { residual } \\
\text { solvents } \\
{[20,14]}\end{array}$ & 2016 \\
\hline 6. & ICH Q3D & $\begin{array}{ll}\text { Guideline } & \text { for } \\
\text { Elemental } & \\
\text { Impurities } & {[20,} \\
\text { 23]. } & \end{array}$ & 2014 \\
\hline 7. & $\begin{array}{l}\text { US-FDA- } \\
\text { NDAs }\end{array}$ & $\begin{array}{l}\text { Impurities in } \\
\text { New Drug } \\
\text { Substances [24] }\end{array}$ & 1998 \\
\hline 8. & $\begin{array}{l}\text { US-FDA- } \\
\text { "ANDAs }\end{array}$ & $\begin{array}{l}\text { Impurities in } \\
\text { New Drug } \\
\text { Substances [7] }\end{array}$ & 1999 \\
\hline 9. & $\begin{array}{l}\text { Therapeutic } \\
\text { Governance } \\
\text { Authority } \\
\text { (TGA), }\end{array}$ & $\begin{array}{l}\text { Australian } \\
\text { regulatory } \\
\text { guideline for } \\
\text { prescription } \\
\text { medicines. (25) }\end{array}$ & 2004 \\
\hline
\end{tabular}

Thorough knowledge of the regulatory guidelines on impurity profiling will ease the research on stability studies unfolding many important and critical aspects about crude Unani single drugs that need to be taken care of, before using them in the preparations and bringing them into the market. It will also help in assigning the correct shelf life to the crude single drugs that are used in the Unani system of medicine.
1. ICH Q1AR2 guidelines "stability testing of new drug substances and products," Step 4 version dated 6 February 2003.

This guideline seeks to exemplify the core stability data package for new drug substances and products and underlines the fact that, Information on the stability of the drug substance is an integral aspect of the systematic approach to stability testing. The guideline explains the aim of stability testing, which is to provide evidence on how the quality of a drug substance or drug product varies with time under the influence of a range of environmental factors like temperature, humidity, and light, and to establish a retest period for the drug substance or shelf life of the drug product and recommended storage conditions. It additionally suggests that stress testing of the drug substance can help identify the likely degradation products, which can in turn help establish the degradation pathways and the intrinsic stability of the molecule and validate the stability indicating the power of the analytical procedures used. The nature of stress testing can depend upon the individual drug substance and also the kind of drug product concerned. Examining degradation products underneath stress conditions is beneficial in establishing degradation pathways and developing and confirming appropriate analytical procedures. However, it should not be necessary test specifically for different kinds of degradation products if it's been demonstrated that they're not designed following accelerated or long run storage conditions. In the case of drug products, the design of formal stability studies for a drug product should be based on the behavior and properties of the drug substance, the results from stability studies on the drug substance, and the experience gained from clinical formulation studies. The possible changes to storage conditions and therefore the explanation for the choice of attributes to be tested within the formal stability studies ought to be expressed. Photo-stability testing ought to be conducted at a minimum of one primary batch of the drug product if acceptable. Standard conditions for photo stability testing are explained in ICH Q1B. Any evaluation should take into account not only the assay but also the degradation products and other appropriate attributes. Where applicable, attention should be paid to reviewing the adequacy of the mass balance and stability and degradation performance.

Stability studies ought to embody testing of those attributes of the drug substance that are at risk of modification throughout storage and are possible to influence quality, safety, and/or efficacy. The testing ought to include, as applicable, the physical, chemical, biological, and microbiological attributes. Validated stability-indicating analytical procedures should be applied. Whether and to what extent replication should be performed will depend on the results from validation studies $[20,18]$. 
Indo Global Journal of Pharmaceutical Sciences, 2020; 10(1): 57-68

Table 3. Typical validation characteristics which should be considered.

\begin{tabular}{|c|c|c|c|c|}
\hline \multirow{2}{*}{$\begin{array}{l}\text { Type of analytical procedure } \\
\text { characteristics. }\end{array}$} & \multirow[t]{2}{*}{ Identification } & \multicolumn{2}{|c|}{ Testing for impurities } & \multirow{2}{*}{$\begin{array}{ll}\text { ASSAY } \\
\text { - } & \text { Dissolution } \\
& \text { (measurement only) } \\
\bullet & \text { Content/Potency }\end{array}$} \\
\hline & & $\begin{array}{l}\text { Quantitative } \\
\text { test }\end{array}$ & $\begin{array}{l}\text { Limit } \\
\text { test }\end{array}$ & \\
\hline Accuracy & - & + & - & + \\
\hline Precision $\quad$ Repeatability & - & + & - & + \\
\hline Interim Precision & - & $+(1)$ & - & $+(1)$ \\
\hline Specificity (2) & + & + & + & + \\
\hline Detection Limit (3) & - & $-(3)$ & + & - \\
\hline Quantitation Limit & - & + & - & - \\
\hline Linearity & - & + & - & + \\
\hline Range & - & + & - & + \\
\hline
\end{tabular}

- Signifies that this characteristic is not normally evaluated,+ signifies that this characteristic is normally evaluated, (1) in cases where reproducibility (see glossary) has been performed, intermediate precision is not needed, (2) lack of specificity of one analytical procedure could be compensated by other supporting analytical procedure(s), (3) may be needed in some cases [20,21].

\section{ICH Q2B Validation of Analytical Procedures: Methodology Step four November 1996.}

This document presents a discussion of the characteristics to be considered in the process of the validation of the analytical procedures involved. Validation of an analytical procedure aims is to demonstrate that it's appropriate for its meant purpose. A tabular summation of the characteristics applicable to identification, management of impurities and assay procedures are listed in Table 3.

The discussion of the validation of analytical procedures is directed to the four commonest varieties of analytical procedures:

- Identification tests;

- Quantitative tests for impurities' content;

- Limit tests for the management of impurities;

- Quantitative tests of the active moiety in samples of a drug substance or drug product or different chosen component(s) within the drug product.

Although there are several different analytical procedures, like dissolution testing of drug product or particle size determination for drug substance, these haven't been addressed within this guidance. A quick description of the kinds of tests discussed within this document is provided below:

- Identification tests are meant to confirm the identity of an analyte within a sample. This is often commonly achieved by comparison of a property of the sample (e.g., spectrum, chromatographic behavior, chemical reactivity, etc.) with that of a reference standard;

Testing for impurities is either a quantitative test or a limit test for the impurity within a sample. Either test is meant to accurately show the purity characteristics of the sample. Completely different validation characteristics are needed for a quantitative test than for a limit test;
- $\quad$ Assay procedures are meant to quantify the analyte that is there in a given sample. Within the context of this document, the assay represents a quantitative measure of the main component(s) within the drug substance. For the drug product, similar validation characteristics additionally apply once assaying for the active or different chosen component(s). Similar validation characteristics might also apply to assays related to different analytical procedures (e.g., dissolution). The intention of the analytical procedure ought to be clearly understood since this can govern the validation characteristics which require to be evaluated.

Moreover, revalidation could also be necessary within the following circumstances:

- Changes within the synthesis of the drug substance;

- Changes within the composition of the finished product;

- Changes within the analytical procedure. The degree of revalidation needed depends on the character of the changes. Many different changes might also need validation $[20,21]$.

\section{ICH Q3A(R) Impurities in New Drug Substances Step four February 2002}

This document is meant to give guidelines for registration applications on the content and qualification of impurities in new drug substances made by chemical syntheses. It is not advisable to use new drug substances used in the clinical research stage of development. Impurities in new drug substances are addressed from 2 perspectives:

- Chemistry Aspects embody classification and identification of impurities, report generation, a listing of impurities in specifications, and a short discussion of analytical procedures; and 


\section{Indo Global Journal of Pharmaceutical Sciences, 2020; 10(1): 57-68}

Safety Aspects embody specific guideline for qualifying those impurities that weren't in the, or were included at considerably lower levels, in batches of a brand new drug substance employed in safety and clinical studies.

This guideline has discussed the following:

- Classification of impurities,

- Rationale for the reportage and management of impurities,

- Analytical procedures,

- Reporting impurity content of batches,

- Listing of impurities in specifications,

- Qualification of impurities and

- Glossary which has definitions many terminologies employed in the rules and are of importance [20, 13].

\section{ICH Q3B(R) Impurities in New Drug product (16) Step four February 2003.}

This guideline has been 1st revised and finalized in Step four in February 2003. It enhances guidance on impurities in new drug substances and provides a recommendation concerning impurities in products containing new, chemically synthesized drug substances. The guidance specifically deals with those impurities which could arise as a degradation product of the drug substance or arising from interactions between drug substance and excipients or elements of primary packaging materials. The guidance sets out an explanation for the reportage, identification and qualification of such impurities based upon a scientific appraisal of possible and actual impurities discovered, and of the safety implications, following the principles detailed within the parent guideline. Threshold values for reporting and management of impurities are suggested based upon the maximum daily dose of the drug substance administered within the product [20, 22].

\section{ICH Q3C (R6) "Impurities: Guidelines for residual solvents" Step four October 20, 2016.}

The objective of this guideline is to suggest acceptable amounts of residual solvents in pharmaceuticals for the safety of the patient. This guideline recommends the use of less poisonous solvents and describes levels thought of toxicologically acceptable for a few residual solvents. Residual solvents in the manufactured drugs are described as, "organic volatile chemicals that are used or made within the manufacture of drug substances or excipients, or within the preparation of drug products". The solvents aren't utterly removed by practical manufacturing techniques. A suitable choice of the solvent for the synthesis of drug substance could enhance the yield, or verify characteristics like crystal form, purity, and solubility. Therefore, the solvent might typically be a vital parameter within the synthetic method. This guideline doesn't address solvents deliberately used as excipients nor will it address solvates. However, the content of solvents in such a product ought to be evaluated and authenticated. Since there's no therapeutic advantage in residual solvents, all residual solvents ought to be removed to the extent valid enough to satisfy product specifications, sensible pharmaceutical preparation practices, or different qualitybased needs. Drug product ought to contain no higher levels of residual solvents than will be supported by safety information. This guideline has also classified the residual solvents. They were evaluated for their possible risk to human health and placed into one of three classes and the terms, "tolerable daily intake" (TDI), "acceptable daily intake" (ADI) and "permitted daily exposure" (PDE) are employed by the International Program on Chemical Safety (IPCS), World Health Organization (WHO) other national and international health authorities and institutes, to describe exposure limits of toxic chemicals [20, 14].

This guideline has also specified the limits for residual solvents, as follows:

Class 1 solvents: Some solvents that are known to cause unacceptable toxicities (Table 4) or Solvents to be avoided in the production of drug substances, excipients, or drug products unless their use may be powerfully even in a very risk-benefit assessment. These are better-known human carcinogens, strongly suspected human carcinogens, and environmental hazards.

Table 4. Class 1-solvents in pharmaceutical products (solvents that should be avoided)

\begin{tabular}{|l|l|l|}
\hline Solvent & $\begin{array}{l}\text { Concentration } \\
\text { Limit } \mathbf{( P p m )}\end{array}$ & Concern \\
\hline Benzene & 2 & Carcinogen \\
\hline $\begin{array}{l}\text { Carbon } \\
\text { tetrachloride }\end{array}$ & 4 & $\begin{array}{l}\text { Toxic } \\
\text { environmental } \\
\text { hazard }\end{array}$ \\
\hline $\begin{array}{l}1,2- \\
\text { Dichloroethane }\end{array}$ & 5 & Toxic \\
\hline $\begin{array}{l}1,1- \\
\text { Dichloroethene }\end{array}$ & 8 & Toxic \\
\hline $\begin{array}{l}1,1,1- \\
\text { Trichloroethane }\end{array}$ & 1500 & $\begin{array}{l}\text { Environmental } \\
\text { hazard }\end{array}$ \\
\hline
\end{tabular}

[(www.ICH.org, ICH Q3C (R6)-2016)-Google scholar]

Class 2 solvents: Some solvents associated with less severe toxicity (Table 5) or Solvents to be limited to protect patients from potential adverse effects. Non-genotoxic animal carcinogens or possible causative agents of alternative irreversible toxicity like neurotoxicity or teratogenicity. Solvents suspected of other significant, but reversible toxicities.

Table 5. Class 2-solvents in pharmaceutical products (solvents that should be limited)

\begin{tabular}{|l|l|l|}
\hline Solvent Concentration & PDE (Mg/Day) & Limit (Ppm) \\
\hline Acetonitrile & 4.1 & 410 \\
\hline Chlorobenzene & 3.6 & 360 \\
\hline Chloroform & 0.6 & 60 \\
\hline Cumene & 0.7 & 70 \\
\hline
\end{tabular}


Indo Global Journal of Pharmaceutical Sciences, 2020; 10(1): 57-68

\begin{tabular}{|l|l|l|}
\hline Cyclohexane & 38.8 & 3880 \\
\hline 1,2-Dichloroethene & 18.7 & 1870 \\
\hline Dichloromethane & 6.0 & 600 \\
\hline 1,2-Dimethoxyethane & 1.0 & 100 \\
\hline N,N-Dimethylacetamide & 10.9 & 1090 \\
\hline N,N-Dimethylformamide & 8.8 & 880 \\
\hline Toluene & 8.9 & 890 \\
\hline 1,1,2-Trichloroethene & 0.8 & 80 \\
\hline Xylene & 21.7 & 2170 \\
\hline
\end{tabular}

[(www.ICH.org, ICH Q3C (R6)- 2016)-Google scholar]

Class 3 solvents: Ideally, less toxic solvents (Table 6), should be used where practical. Solvents with low unhealthful potential to man; no health-based exposure limit is required. Class three solvents have PDEs of fifty mg or a lot of per day. The solvents for which no adequate toxicological data was found are listed in Table 6.

Table 6. Class 3-solvents which should be limited by GMP or other quality-based requirements.

\begin{tabular}{|l|l|l|}
\hline Acetic acid & Ethyl acetate & $\begin{array}{l}\text { 2-Methyl-1- } \\
\text { propanol }\end{array}$ \\
\hline Acetone & Ethyl ether & $\begin{array}{l}\text { 3-Methyl-1- } \\
\text { butanol }\end{array}$ \\
\hline Anisole & Ethyl formate & Pentane \\
\hline 1-Butanol & Formic acid & 1-Pentanol \\
\hline 2-Butanol & Heptane & 1-Propanol \\
\hline Butyl acetate & Isobutyl acetate & 2-Propanol \\
\hline $\begin{array}{l}\text { tert-Butylmethyl } \\
\text { ether }\end{array}$ & Isopropyl acetate & Propyl acetate \\
\hline Dimethyl sulfoxide & Methyl acetate & Triethylamine \\
\hline Ethanol & $\begin{array}{l}\text { Methyl ethyl } \\
\text { ketone }\end{array}$ & \\
\hline
\end{tabular}

[(www.ICH.org, ICH Q3C (R6)-2016)-Google scholar]

\section{ICH Q3D "guidelines for elemental impurities" Step four December 16, 2014.}

The guideline applies to new drug formulations or preparations (as outlined in ICH Q6A and Q6B) and new drug merchandise containing existing drug substances. The drug merchandise containing sublimate proteins and polypeptides, their derivatives, and products of which they are components (e.g., conjugates) are within the scope of this guideline, as are drug products containing synthetically produced polypeptides, polynucleotides, and oligosaccharides. As the industrial method is developed, the principles contained in this guideline can be useful in evaluating elemental impurities that may be present in a new drug product $[19,23]$.

Elemental impurities in drug merchandise might arise from many sources; they might be residual catalysts that were value-added designedly in synthesis or might be there as impurities (e.g., through interactions with process instrumentality or container/closure systems or by being gifted in parts of the drug product). Because elemental impurities don't offer any therapeutic profit to the patient, their levels in

$[19,23]$.

There are three parts of this guideline:

- The evaluation of the toxicity data for potential elemental impurities;

- The establishment of a Permitted Daily Exposure (PDE) for each element of toxicological concern; and

- Application of a risk based approach to control elemental impurities in drug products. The PDEs established during this guideline are thought-about to be protecting of public health for all patient populations.

In some cases, lower levels of elemental impurities may be warranted when levels below toxicity thresholds have been shown to have an impact on other quality attributes of the drug product (e.g., element catalyzed degradation of drug substances). Besides, for elements with high PDEs, other limits may have to be considered from a pharmaceutical quality perspective and other guidelines should be consulted (e.g., ICH Q3A). This guideline presents a method to assess and manage elemental impurities within the drug product adopting the principles of risk management as discussed in ICH Q9. This process provides a platform for developing a risk-based control strategy to limit elemental impurities [19, 23].

The elements enclosed during this guideline are placed into 3 categories supported their toxicity (PDE) and the chance of incidence within the drug product.

Impurities in the drug product.

\section{The elemental impurity classes are:}

Class 1: The elements, $\mathrm{As}, \mathrm{Cd}, \mathrm{Hg}$, and $\mathrm{Pb}$, are human toxicants that have limited or no use in the manufacture of pharmaceuticals. Their presence in drug merchandise usually comes from ordinarily used materials (e.g., mined excipients). Because of their unique nature, these four elements require evaluation during the risk assessment, across all potential sources of elemental impurities and routes of administration.

Class 2: Elements in this class are generally considered as a route-dependent human toxicant. Class 2 elements are further divided into sub-classes $2 \mathrm{~A}$ and $2 \mathrm{~B}$ based on their relative likelihood of occurrence in the drug product.

- Class 2A elements have a relatively high probability of occurrence in the drug product and thus require risk assessment across all potential sources of elemental impurities and routes of administration (as indicated). The class $2 \mathrm{~A}$ elements are $\mathrm{Co}, \mathrm{Ni}$, and $\mathrm{V}$.

- Class 2B elements have a reduced probability of occurrence in the drug product related to their low abundance and low potential to be co-isolated with other materials. As a result, they may be excluded from the risk assessment unless they are intentionally added during the manufacture of drug substances, excipients or other components of the drug product. The elemental 
Indo Global Journal of Pharmaceutical Sciences, 2020; 10(1): 57-68

impurities in class 2B include: $\mathrm{Ag}, \mathrm{Au}, \mathrm{Ir}, \mathrm{Os}, \mathrm{Pd}, \mathrm{Pt}, \mathrm{Rh}$, $\mathrm{Ru}, \mathrm{Se}$ and $\mathrm{Tl}$.

Class 3: The elements within this category have comparatively low toxicities by the oral route of administration (high PDEs, generally > $500 \mu \mathrm{g} /$ day) but may require consideration in the risk assessment for inhalation and parenteral routes. For oral routes of administration, unless these elements are intentionally added, they do not need to be considered during the risk assessment. For parenteral and inhalation product, the potential for inclusion of these elemental impurities should be evaluated during the risk assessment, unless the route specific PDE is above 500 $\mu \mathrm{g} /$ day. The elements in this class include: $\mathrm{Ba}, \mathrm{Cr}, \mathrm{Cu}, \mathrm{Li}, \mathrm{Mo}$, $\mathrm{Sb}$, and Sn. Other elements: Some of the elements considered include: Al, B, Ca, Fe, K, Mg, Mn, Na, W and Zn [19, 23].

In considering the manufacture of a drug product, there are broad categories of potential sources of elemental impurities.

- Residual impurities resulting from elements intentionally added (e.g., catalysts) in the formation of the drug substance, excipients or other drug product components. The risk assessment of the drug substance ought to address the potential for inclusion of elemental impurities within the drug product.

- $\quad$ Elemental impurities that are not intentionally added and are potentially present in the drug substance, water or excipients used in the preparation of the drug product.

- $\quad$ Elemental impurities that are potentially introduced into the drug substance and/or drug product from manufacturing equipment.

- Elemental impurities that have the potential to be leached into the drug substance and drug product from container closure systems.

Each of those sources might contribute elemental impurities to the drug product, through anyone or any combination of the potential sources listed above. During the risk assessment, the potential contributions from each of these sources should be considered to determine the overall contribution of elemental impurities to the drug product.

As a need of the importance of the noted elemental impurity level, a control threshold is defined as, "a level that is $30 \%$ of the established PDE in the drug product. The control threshold is also accustomed to determine if extra controls are also needed. If the overall elemental impurity level from all sources within the drug product is predicted to be systematically less than $30 \%$ of the PDE, then additional controls are not required, provided the applier suitably assessed the information and laid down adequate controls on elemental impurities. If the risk assessment fails to demonstrate that an elemental impurity level is systematically less than the management threshold, controls should be established to ensure that the elemental impurity level doesn't exceed the PDE within the drug product $[19,23]$.

Controls of elemental impurities are one part of the management strategy for a drug product that assures that elemental impurities don't exceed the PDEs. When the extent of an elemental impurity might exceed the management threshold, additional measures should be implemented to assure that the level does not exceed the PDE. Approaches that an applier will pursue may, however, don't seem to be restricted to:

- Modification of the steps in the manufacturing process that result in the reduction of elemental impurities below the control threshold through specific or nonspecific purification steps;

- Implementation of in-process or upstream controls, designed to limit the concentration of the elemental impurity below the control threshold in the drug product;

- $\quad$ Establishment of specification limits for excipients or materials (e.g., synthetic intermediates);

- Establishment of specification limits for the drug substance;

- Establishment of specification limits for the drug product;

- Selection of appropriate container closure systems.

Periodic testing is also applied to elemental impurities in line with the principles mentioned in ICH Q6A [19, 23].

7. US-FDA guidelines "NDAs -Impurities in New Drug Substances" [24].

8. US-FDA guidance "ANDAs - Impurities in New Drug Substances" [7].

9. Australian regulatory guideline for prescription medicines, Therapeutic Governance

Authority (TGA), Australia [25].

\section{CONCLUSION}

It is important to understand the impurity profiles of drug products and drug substance material. Assessing the purity of the sample allows pharmaceutical companies to make decisions during the development and to move forward through the commercialization of the drug. Impurity profiles dictate raw material quality from vendors, finished product shelf life, route synthesis pathways and intellectual protection from counterfeiting. The ability to understand the levels of pharmaceutical impurities is not only a regulatory necessity but a business imperative. Analytical determination of impurities is often time constraining and resource consuming. Analysts require a range of mass spectrometry capabilities as well as sophisticated software to facilitate data processing of these complex impurity data sets. There is a need for such solutions that help shape the approaches and the landscape of the pharmaceutical laboratory focusing on implementing streamlined pathways to understanding and controlling impurities. 


\section{Indo Global Journal of Pharmaceutical Sciences, 2020; 10(1): 57-68}

\section{ACKNOWLEDGEMENT}

The author Dr Ameena Yasmeen, would like to acknowledge Dr Mansoor Ahmad Siddiqui, Ex-Director N.I.UM for providing the opportunity to pursue doctoral research at National Institute of Unani Medicine, Kottigepalya, Magadi main Road, Bengaluru. and would also like to acknowledge $\mathrm{Dr}$ Abdul Wadud, the present director of National Institute of Unani Medicine, Bengaluru for helping choose, "Stability Studies" as the topic for the doctoral research. Lastly, the authors would also like to acknowledge Rajiv Gandhi University of Health Sciences, Jayanagar, Bengaluru, Karnataka, India.

\section{AUTHOR'S CONTRIBUTION}

Dr Ameena Yasmeen, the first author \& corresponding author of this manuscript carried out literature search from Books, Internet, Journals etc., and is responsible for the concept, design and drafting of this study, while the second author, Dr Ghulamuddin Sofi, (my Guide), has helped by critically revising the manuscript for important intellectual content and the third author, Dr Kaleemullah khan, contributed in collection of the data and final drafting of the manuscript. All the authors have checked and approved the final version of the manuscript.

\section{CONFLICT OF INTEREST}

The authors have no conflicts of interest.

\section{SOURCES OF FUNDING}

None of the authors involved in the manuscript have received any fellowship from any agency.

\section{REFERENCES}

1. Kokate CK, Purohit, AP. and Gokhale SB: Pharmacognosy. Nirali Prakashan. Pune, 51 ${ }^{\text {ST }}$ Edition 2015: 3.24.

Sharma S. Degradation and characterization of impurities of new drug candidate using advance analytical techniques. J Anal Bioanal Tech. 2015; 6(4):151.

3. Venkatesan P, Valliappan K. Impurity Profiling: Theory and Practice. J. Pharm. Sci. \& Res. 2014; 6(7): 254-259.

4. Impurity analysis of raw materials and final product. Available from URL http://www.waters.com/waters/en_in/impurity-analysisof-raw-materials-and-final-

product/nav.htm?cid=134752664\&locale=en_in. Assessed on 07/03/2019.

5. Ruhela G, Kaushik D. Regulatory Aspects for Impurity Profiling Of Pharmaceutical Products: An Overview. Int J Pharm Sci Res. 2017; 8(7): 2808-14.

Zanowiak P: Encyclopedia of Chemical Technology, KirkOthmer (Ed.), Fourth ed., Vol. 18, Wiley, Chi Chester, 1996: 480.
7 . for industry, US Food and Drug Administration, Center for Drug Evaluation and Research, Department of Health and Human Services, 1999; pp.198.

8. ICH.Q3A. International Conference on Harmonization: Impurities in New Drug Substances and ICH.Q3B, (1997) International Conference on Harmonization: impurities in New Drug products. 1996

Anonymous. The United States Pharmacopoeia 24, USP Convention, Inc., Rockville, 2000:1876 and 2049.

10. Maggon KK, Mechkovsi A. Drug News Perspect.1992; Vol 5, pp. 261.

11. Erni F, Helboe P. Pharma Times. 1996; vol 10: 9.

12. ICH Topic Q3 A. Impurities Testing Guideline: Impurities in New Drug Substances, The European Agency for the Evaluation of Medicinal Products Human Medicines Evaluation Unit.1995.

13. $\mathrm{ICH} \mathrm{Q} 3 \mathrm{~A}(\mathrm{R})$. International Conference on Harmonization: Impurities in New Drug Substances," Step 5. 2002.

14. ICH Q3C(R6). International Conference on Harmonization: Impurities: Guideline for Residual Solvents" Current Step 4 version, dated $20^{\mathrm{TH}}$ October 2016.

15. Fake, A. Establishing Impurity Specifications. WHO. From internet. Assessed on 07/03 /2019.

16. www.authorstream.com (Impurity Profiling| author STREAM) http://www.authorstream.com/ Presentation /ravi.udhan 403 1507506-impurity/assessed on 0703/2019.

17. www.pharmatutor.org https://www.pharmatutor.org/articles/impurity-profiling $\quad 10 /$, assessed on 07/03/2019.

18. ICH Q1A (R2). International Conference on Harmonization: Stability Testing of New Drug Substances and Products," Step 4 version dated 6 February 2003.

19. ICH Q2B. International Conference on Harmonization, Validation of Analytical Procedures: Terms and Definitions," Step $5,1996$.

20. Www.ICH.org assessed on 07/03/2019.

21. $\mathrm{ICH} \mathrm{Q} 3 \mathrm{~B}(\mathrm{R})$. International Conference on Harmonization: Impurities in New Drug Products," Step 5, 2003.

22. ICH Q3D. International Conference on Harmonization " Guideline for Elemental Impurities" Current Step 4 version dated 16 December 2014.

23. US-FDA NDAs. Guidance for Industry (Draft): Stability Testing of Drug Substances and Drug products. FDA. Rockville, MD. 1998.

24. US-FDA ANDAs. Guidance for Industry (Draft): CMC Content and Format, INDs for Phase 2 and 3 Studies of Drugs, Including Specified Therapeutic Biotechnology-Derived Products. FDA. Rockville, MD.1999.

25. Ahuja S and Alsante KM. Handbook of Isolation and Characterization of Impurities in Pharmaceuticals. Sep Sci Technol., Academic press. 2003; Vol. 5. 